\title{
Centralization of Esophagectomy in the United States: Might It Benefit Underserved Populations?
}

\author{
David T. Cooke, MD \\ Section of General Thoracic Surgery, UC Davis Health, Sacramento, CA
}

For four decades, there has been nearly irrefutable evidence that higher programmatic surgical volume leads to reduced patient mortality for the most complex operations. ${ }^{1}$ At the turn of this century, Birkmeyer et al. clearly identified a volume-outcomes relationship for hospitals performing the procedure esophagectomy. ${ }^{2}$ Esophagectomy, as is pancreatectomy and pneumonectomy, is a "varsity level" surgical procedure, where one would assume that "practice" or doing a lot of said procedures "makes perfect." A literature search in PubMed querying the terms esophagectomy and volume, between the years 2002 (the publication date of Birkmeyer et al. initial paper on the subject) to 2018, yields more than 500 references. Most of those studies support the volume-outcomes relationship for esophagectomy. Although there is no U.S. government mandate for regionalization or centralization of esophagectomy at high-volume centers, there is evidence that the American healthcare system may be voluntarily self-centralizing complex operations to highvolume centers. ${ }^{3}$ This could be via pressure from consumer advocacy organizations, such as the LeapFrog Group, which has established a minimum annual esophagectomy case number of 13 to define hospital quality, or even peerpressure, as evidenced by the "volume pledge" taken by three major academic hospitals regarding annual minimums for esophagectomy.,

However, is centralization of high-risk surgery necessarily a good thing for all patients? There are already great health disparities in patients undergoing treatment for esophageal cancer. African-American patients are less

(C) Society of Surgical Oncology 2018

First Received: 1 March 2018;

Published Online: 19 March 2018

D. T. Cooke, MD

e-mail:dtcooke@ucdavis.edu likely to undergo esophagectomy for esophageal cancer compared with white patients, and rural patients undergoing esophagectomy for cancer are more likely to be operated on at low-volume hospitals. ${ }^{6,7}$ In this issue of the Annals of Surgical Oncology, Schlottmann et al. test the hypothesis that centralization of esophageal cancer surgery is occurring in the United States and is improving mortality outcomes in patients. ${ }^{8}$ Not surprisingly, their analysis supported their hypothesis; however, other findings in their study represent new contributions to the esophagectomy outcomes health disparities literature. Their analysis of the Nationwide Inpatient Sample from the years 2000 to 2014 found that non-white patients and patients of low household income also demonstrated a reduction in hospital mortality after esophagectomy during the study period.

Schlottmann et al.'s study provides both good news and bad news about health disparities for esophageal cancer surgery. The bad news is: (a) their analysis shows that black and Hispanic patients had a much higher mortality after esophagectomy for cancer than white patients; and (b) black and Hispanic patients over the study period were more likely to undergo esophagectomy at low-volume centers than white patients. The good news is: although non-white and patients from low-income households had higher mortality rates compared with white patients and patients from mid- to high-income households in the early years of the analysis, improvements in mortality over time for these at-risk populations occurred at the same rate as white and mid- to high-income patients.

The authors' study suggests that some health disparities, such as hospital mortality, may improve if vulnerable populations undergo esophagectomy at high volume centers. Although overall mortality for non-white and lowincome patients has improved over the decade of centralization for esophageal cancer, is that because more patients from vulnerable groups are having their operations performed at high-volume centers, or is it because select but 
fewer patients from vulnerable groups are undergoing surgery? In a very recent study, Wasif et al. analyzed the race and socioeconomic characteristics of patients undergoing esophagectomy for cancer and other complex operations at Commission on Cancer $(\mathrm{CoC})$ accredited high-volume hospitals between the years 2003 and 2012. ${ }^{9}$ The authors found that African-Americans and patients from zip codes associated with low household education attainment were less likely to undergo esophagectomy at high-volume $\mathrm{CoC}$ centers. Those differences persisted for the entire study period, which was essentially the same decade that Schlottmannet al. identified a pattern of centralization of esophagectomy for cancer.

Although compelling, the study by Schlottmann et al. does not provide all the answers about health disparities and esophageal cancer surgery. However, the results present to investigators additional insight into a difficult-tosolve issue. To improve the outcomes of our most vulnerable populations, we either must develop methods to facilitate access to centralized, high-volume centers, or we translate the institutional knowledge, best practices and recovery and rescue pathways from our centralized programs to the communities where our most vulnerable populations may reside.

\section{REFERENCES}

1. Luft HS, Bunker JP, Enthoven AC. Should operations be regionalized? The empirical relation between surgical volume and mortality. N Engl J Med. 1979;301(25):1364-9.
2. Birkmeyer JD, Siewers AE, Finlayson EV, Stukel TA, Lucas FL, Batista I, et al. Hospital volume and surgical mortality in the United States. N Engl J Med. 2002;346(15):1128-37.

3. Finks JF, Osborne NH, Birkmeyer JD. Trends in hospital volume and operative mortality for high-risk surgery. $N$ Engl $J$ Med. 2011;364(22):2128-37.

4. Birkmeyer JD, Dimick JB. Potential benefits of the new Leapfrog standards: effect of process and outcomes measures. Surgery. 2004;135(6):569-75.

5. Sternberg S. Hospitals move to limit low-volume surgeries. U.S. News and World Report. 2015. Available at: http://www.usnews. com/news/articles/2015/05/19/hospitals-move-to-limit-low-volumesurgeries. Accessed 15 Feb 2018.

6. Greenstein AJ, Litle VR, Swanson SJ, Divino CM, Packer S, McGinn TG, Wisnivesky JP. Racial disparities in esophageal cancer treatment and outcomes. Ann Surg Oncol. 2008;15(3):881-8.

7. Liu JB, Bilimoria KY, Mallin K, Winchester DP. Patient characteristics associated with undergoing cancer operations at low-volume hospitals. Surgery. 2017;161(2):433-43.

8. Schlottmann F, Strassle PD, Charles AG, Patti MG. Esophageal cancer surgery: spontaneous centralization in the us contributed to reduce mortality without causing health disparities. Ann Surg Oncol. https://doi.org/10.1245/s10434-018-6339-3. Accessed 22 Jan 2018.

9. Wasif N, Etzioni D, Habermann EB, Mathur A, Pockaj BA, Gray RJ, Chang YH. Racial and socioeconomic differences in the use of high-volume commission on cancer-accredited hospitals for cancer surgery in the United States. Ann Surg Oncol. https://doi.org/10. 1245/s10434-018-6374-0. Accessed 15 Feb 2018. 